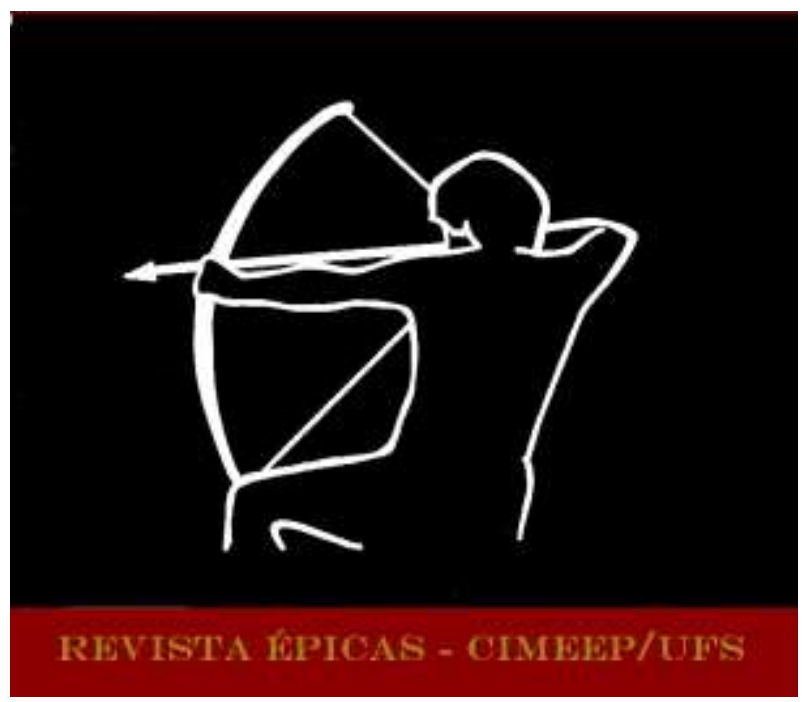

SILVA, Fabio Mario da. Notas de investigação sobre as duas primeiras edições do Memorial da infância de Cristo e Triunfo do divino amor, de Soror Maria de Mesquita Pimentel. In: Revista Épicas. Ano 4, Número 8, Dez 2020, p. 257-265. ISSN 2527-080X. DOI: http://dx.doi.org/10.47044/2527$\underline{080 X .2020 v 8.257266}$

\title{
NOTAS DE INVESTIGAÇÃO SOBRE AS DUAS PRIMEIRAS EDIÇÕES DO MEMORIAL DA INFÂNCIA DE CRISTO E TRIUNFO DO DIVINO AMOR, DE SOROR MARIA DE MESQUITA PIMENTEL
}

\author{
NOTES DE RECHERCHE SUR LES DEUX PREMIÈRES ÉDITIONS DU \\ MEMORIAL DA INFÂNCIA DE CRISTO E TRIUNFO DO DIVINO AMOR, \\ DE SOROR MARIA DE MESQUITA PIMENTEL
}

Fabio Mario da Silva ${ }^{1}$

Universidade Federal do Sul e Sudeste do Pará

Para Adma Muhana, pela supervisão do projeto de pós-doc e pela amizade

Resumo: Nossa proposta é comparar as duas primeiras edições do Memorial da Infância (1638 e 1639), de Soror Maria de Mesquita Pimentel. Iremos refletir sobre os objetivos das duas edições e de como essa descoberta nos ajudou a publicar uma reedição modernizada da obra, revisada e aumentada, em 2019, pela Editora Todas Musas.

Palavras-chave: Soror Maria de Mesquita Pimentel, Memorial da Infância de Cristo e Triunfo do Divino Amor, epopeia, século XVII.

Résumé: Notre proposition est de comparer les deux premières éditions du Memorial da Infância (1638 et 1639), par Soror Maria de Mesquita Pimentel. Nous réfléchirons aux objectifs des deux éditions et à la

${ }^{1}$ Investigador do CLEPUL/ Coordenador do GESG - Univ. de Lisboa. Coordenador do GT 18 ("O épico e as mulheres") do CIMEEP. 
manière dont cette découverte nous a permis de publier une réédition modernisée de l'ouvrage, revue et augmentée, en 2019, par l'Editora Todas Musas.

Mots-clés: Soror Maria de Mesquita Pimentel, Memorial da Infância de Cristo e Triunfo do Divino Amor, épopée, XVIle siècle.

Quando publicamos em 2016, pela Editora Todas as Musas, uma edição modernizada do Memorial da Infância de Cristo e Triunfo do Divino Amor (primeira parte $)^{2}$, tomamos como base a única edição que se conhecia na altura, a da Oficina de Jorge Rodrigues de 1639, referida por Diogo Barbosa Machado (1752), Isabel Morujão (1995, 2013), Antónia Conde (2009), Vanda Anastácio (2013) e Fabio Mario da Silva (2016).

Contudo, durante a preparação da segunda edição do Memorial da Infância e de uma primeira edição do manuscrito (nunca editado) Memorial da Paixão de Cristo $e$ Triunfo do Divino Amor (terceira parte), ambas publicadas em 2019 pela mesma editora, Todas as Musas, descobrimos, afinal, o que seria a primeira edição do Memorial da Infância, a do ano de 1638, intitulada Memorial da infancia de Christo e triumpho do divino amor: poemas em dez cantos de oytava rythma. Tal exemplar é referido no Diccionario Bibliographico Portuguez, por Inoccencio Francisco da Silva, em 1862, páginas 141 e 142. Por ser o único a mencionar a edição de 1638, sem nenhum dos críticos terem localizado tal volume, sempre foi referida a edição de $1639,^{3}$ da Oficina de Jorge Rodrigues, da qual identificou-se apenas três exemplares: um da Biblioteca Pública de Évora, um da Biblioteca Nacional de Espanha, em Madrid, e um da Biblioteca Nacional de Portugal, em Lisboa. O que a crítica moderna reproduz então é a indicação de Barbosa Machado na Bibliotheca luzitana: histórica, crítica e cronologia, obra de 1752, que cita apenas a edição do Memorial de 1639 (às páginas 427 e 428), edição à qual tivemos acesso nas três diferentes bibliotecas às quais nos referimos, comprovando a veracidade do relato de Machado. A mesma informação, inclusive, já comparece no Theatro heroino: abecedario historico, e catalogo de mulheres illustres em armas, letras,

\footnotetext{
2 Esse projeto fez parte de um pós-doutorado realizado na Universidade de São Paulo com bolsa da FAPESP, entre 2013 e 2016, sob supervisão da Professora Doutora Adma Muhana, incluindo um estágio de um ano na Universidade de Lisboa, sob co-supervisão da Professora Doutora Vanda Anastácio.

3 Durante a elaboração da nossa edição do Memorial da Infância, publicada em 2016, citamos o verbete do Inoccencio Silva sobre a autora, no qual consta, sim, a edição de 1638 , com leve alteração no subtítulo. Contudo, como nenhum crítico referia esse exemplar, e na altura não tivemos acesso à edição da Universidade de Toronto, apenas citamos a edição de 1639, pensando ter sido talvez um lapso de Silva, tal como fizeram os outros pesquisadores, que possivelmente tiveram a mesma impressão.
} 
acçoens heroicas e artes liberais, volume II, publicado entre 1736-1740, por Damião de Froes Perym, à página 276.

Supomos que esse desconhecimento da obra de 1638 até os tempos atuais aconteceu porque o único exemplar que se conhece pertence à Universidade de Toronto, uma instituição fora do contexto ibérico e de língua portuguesa. Vale também destacar o acervo da literatura e cultura portuguesas pertencente a essa universidade canadense, que publica muitas obras digitalizadas na plataforma intitulada "Internet archive" (https://archive.org/) - site que possui um acervo digitalizado em constante atualização, com destaque para obras portuguesas, principalmente do século XIX. Na confrontação entre as edições de 1638 e 1639 do Memorial da Infancia de Christo, já notamos uma diferença significativa, nomeadamente na comparação entre as folhas de rosto, muito embora, pela imagem digitalizada do exemplar pertencente à Universidade de Toronto, pareça-nos que estejam ausentes páginas iniciais e finais do livro:

Fig. 1: Edição de 1638, que faz parte do espólio da Universidade de Toronto, Canadá

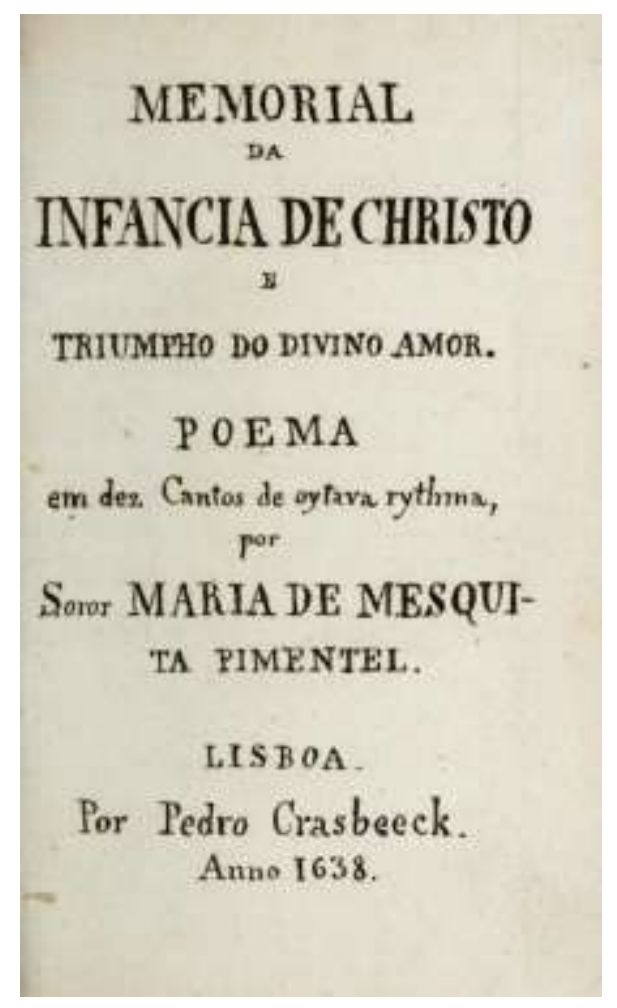

Fig. 2: Edição de 1639, que faz parte do espólio da Biblioteca Nacional de Lisboa

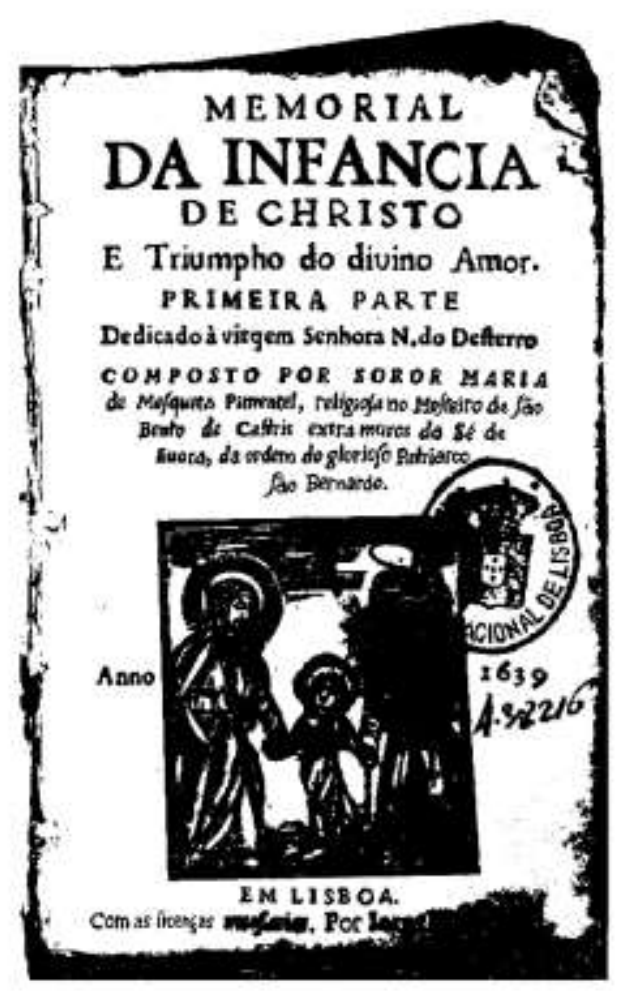


A edição de 1639 troca o subtítulo "Poemas em dez cantos de oitava rima", que consta na edição de 1638, por "Primeira parte", possivelmente porque as duas edições tenham funções e objetivos distintos. Ao nomear poemas em dez cantos de oitava rima, a edição impressa na oficina de Pedro Cra[e]sbeeck - que foi tipógrafo, impressor e editor muito importante na altura - tem talvez a intenção de acentuar o caráter épico da edição. Lembremos que a família Craesbeeck possuía uma longa tradição no mercado seiscentista português, sendo a casa editorial responsável por publicar a primeira edição de Peregrinação, de Fernão Mendes Pinto, e várias edições de Os Lusíadas, de Luís de Camões. Devido à publicação de Os Lusíadas, épico já com destacado reconhecimento, cremos que a oficina de Pedro Craesbeeck teve real interesse na publicação do Memorial da Infância, uma vez que a obra adotava também o gênero épico como estrutura narrativa e por também perceber, provavelmente, as similitudes entre a obra de Camões e a de Soror Pimentel.

Já quando, na oficina de Jorge Rodrigues, altera-se o subtítulo para "primeira parte", o que se quer acentuar é a continuação da obra, prevendo a possível publicação - que não ocorreu na altura - da trilogia épica de Soror Pimentel: Memorial da Infância de Cristo $e$ Triunfo do Divino Amor (primeira parte), Memorial dos Milagres de Cristo e Triunfo do Divino Amor (segunda parte) e Memorial da Paixão de Cristo e Triunfo do Divino Amor (terceira parte) - tarefa essa que assumimos aquando da publicação modernizada da trilogia, a partir de 2016.

Na capa da edição de 1639 constam diversos elementos textuais, entre os quais a dedicatória à Virgem Senhora Nossa do Desterro - paratexto que não encontramos na versão digitalizada pela Universidade de Toronto. Outro enfoque e destaque na capa de 1639 é a indicação da ordem à qual pertencia a autora, São Bernardo, e onde estava professa, no mosteiro de São Bento de Castris, em Évora, como quem procura fornecer ao leitor informações sobre a escritora - dados ausentes no frontispício de 1638. Um outro destaque importante na capa da edição de 1639 é a referência de que a obra possui "as licenças necessárias", indicando que o texto passou pelo crivo dos censores e que, assim sendo, a obra estaria em consonância com as normas estabelecidas para publicação.

Ora, a edição do espólio da Universidade de Toronto apenas apresenta duas licenças: a primeira, de 1635, do Frei Arsenio da Paixão, abade geral; e, depois, uma outra de 1633, do Frei Theodosio de Lucena. Entretanto, na edição de Jorge Rodrigues encontramos diversas licenças, assinadas por Frei Damaso da Apresentação (1636); pelo Doutor Frei Gaspar dos Reis 
(1637); por Manoel da Cunha P. da Silva, F. Cardoso de Torne, Diogo Osorio de Castro e Sebastião Cesar de Meneses, que assinam juntos a mesma licença (1637); por Francisco da Mota Pessoa (1637); por Carvalho Pereira (1637); por Frei Theodosio de Lucena (1633); e, por fim, por Frei Arsenio da Paixão, abade geral (1635). ${ }^{1}$ Poderíamos até conjeturar que, na edição da Universidade de Toronto, as páginas das licenças faltantes tivessem sido arrancadas, mas a digitalização disponível não nos permite afirmá-lo. Contudo, a certeza que podemos ter é a de que as edições não reproduzem a mesma matriz dos paratextos, porque há diferenças, seja na ordem em que aparecem os censores, seja no conteúdo com leves alterações, indicando duas matrizes diferentes para a impressão dessas licenças, como o uso de maiúsculas e minúsculas e da pontuação.

\section{Exemplo 1:}

a)

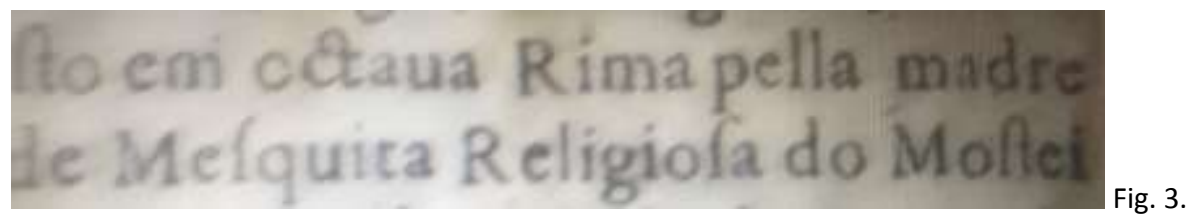

Edição de 1638, na licença de Frei Theodosio de Lucena, o vocábulo "Rima" está grafado em maiúsculas.

b)

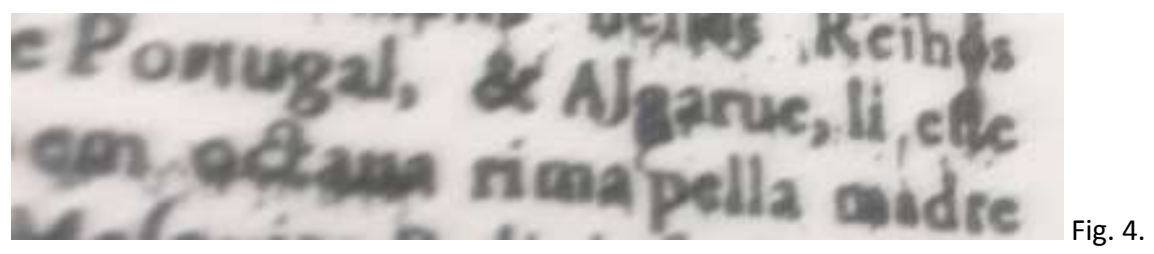

Na edição de 1639, na licença de Frei Theodosio de Lucena, o lexema "rima" vem em letra minúscula.

\footnotetext{
${ }^{1}$ Como se vê, as licenças não foram publicadas por ordem cronológica e tampouco por ordem de importância ou estatuto
} dos censores. 
Exemplo 2:

a)

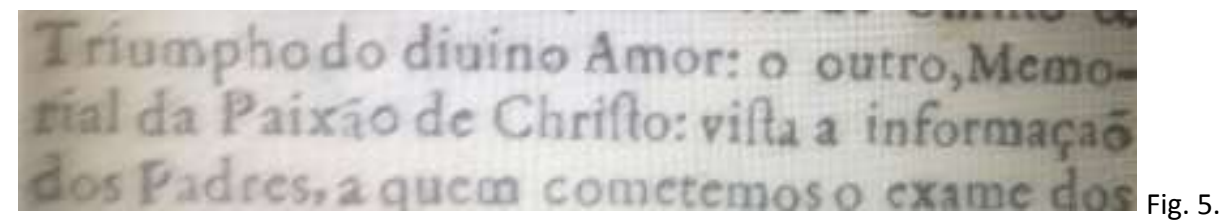

Na edição de 1638, na licença do Frei Arsenio da Paixão, o trecho “Amor: o outro" está grafado diferentemente da edição de 1639 , devido ao uso da letra minúscula e da pontuação.

b)

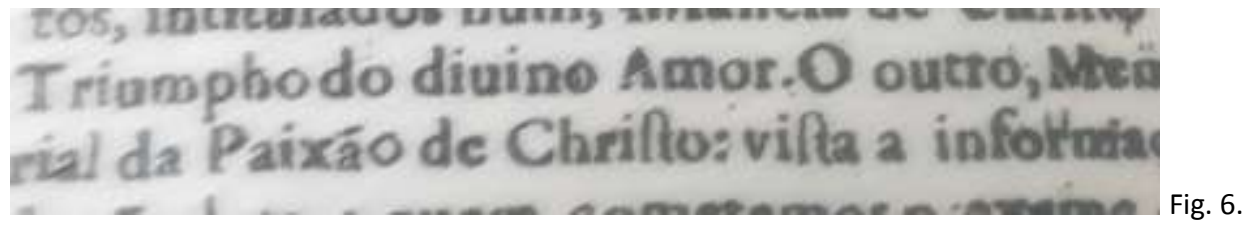

Na edição de 1639, na licença do Frei Arsenio da Paixão, o trecho “Amor. O outro" está grafado diferentemente da edição de 1638 , com a troca dos dois pontos pelo ponto final e, logo em seguida, pela maiúscula no artigo "o".

No Memorial da Infância de 1639 também encontramos um número maior de poemas dedicados à autora, dois dos quais não constam na edição de 1638 e cujos títulos são "À senhora Maria de Mesquita em a presente obra", do Padre João de Teve e Marmeleiro, e "Décimas", do Padre Luiz Mendes, com versos dedicados à autora exaltando a sua obra, as suas qualidades, o seu "alto engenho". A simplicidade constatada na edição de Pedro Craesbeeck diferencia-se no cuidado da de Jorge Rodrigues, com a escolha de uma imagem visualmente muito apelativa dentro de um Portugal católico, sob domínio filipino e inquisitorial: a da Sagrada Família - imagem que ilustra a própria infância de Cristo e que reproduzimos na nossa edição modernizada, a partir de um afresco que a autora talvez tivesse visto em Évora, no oratório das Casas Pintadas, do século XVII - o qual por si só já constitui um aspecto visual que certamente chamaria a atenção do leitor na altura e despertaria a sua curiosidade e desejo em conhecer a obra.

Em relação ao conteúdo das epopeias, na confrontação das duas edições, percebemos que elas reproduzem a mesma matriz, mas a edição de 1639 possui uma errata antes do 
primeiro canto, demonstrando o cuidado com a edição, fato que desperta suspeitas de que, quem sabe, a autora tivesse mandado emendar alguns detalhes nessa edição de 1639, após a impressão de 1638:

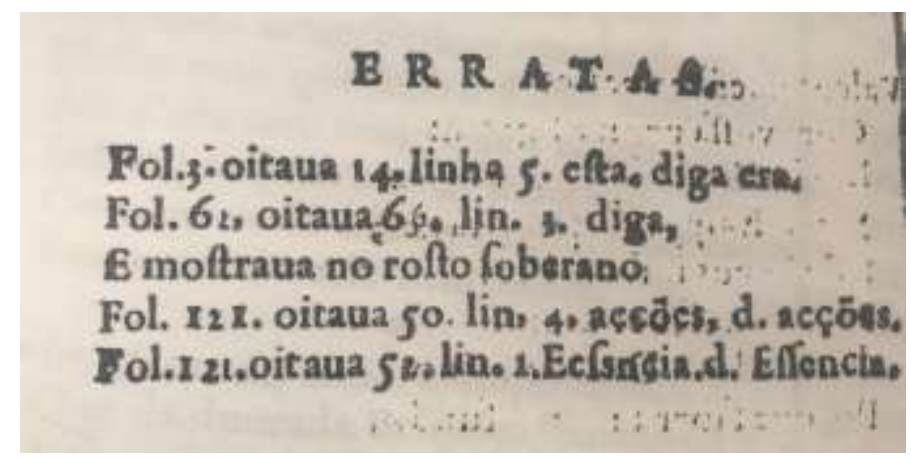

Fig. 7: Errata que consta na edição do Memorial de 1639.

Um outro aspecto importante da edição de 1638, da Universidade de Toronto, é o conjunto de indicações das posses da obra, visto que nela constam dois ex-libris: um primeiro, atrás da encadernação da capa do volume, da Livraria de José Maria de Nepomuceno (18361895); e um segundo, no verso da contracapa, indicando o nome de Annibal Fernandes Thomaz (1849-1901), dois importantes bibliófilos e bibliógrafos portugueses que tiveram suas bibliotecas catalogadas e depois vendidas em leilões. Ora, isso indica que Annibal Thomaz deve ter adquirido o exemplar de Memorial da infancia de Christo e triumpho do divino amor: poemas em dez cantos de oytava rythma na livraria de Nepomuceno. Sendo assim, esse exemplar raro do Memorial, durante o século XIX, terá pertencido aos dois famosos bibliográfos, o que, após um longo período ignorado, possibilitou o conhecimento da edição por parte de Inocêncio da Silva.

Seguindo o paradeiro do volume de 1638, constatamos que é publicado em 1912 o catálogo da Biblioteca de Annibal Fernandes Thomaz e encontramos, na página 217, a referência à edição do Memorial de 1638. Não sabemos o que aconteceu depois da venda do dito exemplar mas, possivelmente, no começo do século XX a obra ainda estava em território português. O que sabemos até o momento é que o exemplar da universidade canadense foi oferecido à Biblioteca da Universidade de Toronto pelo Professor Ralph G. Stanton (19232010), professor fundador da Faculdade de Matemática da Universidade de Waterloo, o qual possuía uma das maiores coleções privadas de literaturas portuguesa e francesa, e é 
considerado um dos maiores colecionadores do mundo de literatura portuguesa clássica. 0 Professor Stanton doou o seu espólio à Universidade de Toronto em $1988 .{ }^{2}$

Quanto ao Theatro heroino de Damião de Froes Perym, já citado, revelar mais algumas pistas sobre a erudição da Soror Pimentel, chamando a atenção para o fato de que essa monja teria sido uma poetisa muito celebrada no seu século (cf. PERYM, [1740], p. 276), o que talvez signifique que existam outros escritos poéticos da autora para além de sua epopeia, que terão circulado em âmbito restrito. Isto quer dizer que ainda podemos, quem sabe?, descobrir algum manuscrito da sua trilogia épica (Memorial da Infância, Memorial dos Milagres e Memorial da Paixão), ou algum outro texto da autora aguardando revelação.

Por fim, tendo em vista esses novos dados sobre a edição de 1638 do Memorial da Infância e considerando ter-se esgotado a nossa primeira edição modernizada dessa obra, publicada em 2016, decidimos reeditar a obra em uma segunda edição. Esta consiste em uma edição revisada e ampliada do primeiro Memorial, na qual preenchemos algumas lacunas de conteúdo e crítica textual, tendo em vista sobretudo as novas informações trazidas pela obra digitalizada pertencente à Universidade de Toronto.

\section{Referências bibliográficas}

ANASTÁCIO, Vanda. (Org.). Uma antologia improvável: a escrita das mulheres (séculos XVI a XVIII). Lisboa: Relógio d'Água, 2013.

CONDE, Antónia Fialho. Espaço literário feminino. A obra de Soror Maria de Mesquita Pimentel. In: OLIVEIRA, Francisco et al. (Coord.). Espaços e paisagens. Antiguidade clássica e herança contemporânea. Coimbra: APEC, 2009a. p. 353-360. v. 2. Disponível em: $<$ http://dspace.uevora.pt/rdpc/bitstream/10174/3992/1/pimentel\%20apec.pdf $>$. Acesso em: 12 jan. 2020.

CUNHA, Casimiro da. Catálogo da preciosa livraria antiga e moderna que pertenceu ao distincto bibliophilo e bibliographo Annibal Fernandes Tomaz. Lisboa, Tipographico Colonial, 1912.

MACHADO, Diogo Barbosa. Bibliotheca luzitana: histórica, crítica e cronologia. Lisboa: Officina de Antonio Isidoro da Fonseca, 1752. v. 3, p.427-428.

MORUJÃO, Isabel. Contributo para uma bibliografia cronológica da literatura monástica feminina portuguesa dos séculos XVII e XVIII: impressos. Lisboa: Universidade Católica, 1995. MORUJÃO, Isabel. Por trás da grade: poesia conventual feminina em Portugal (séculos XVIXVII). Lisboa: Imprensa Nacional/Casa da Moeda, 2013.

\footnotetext{
2 Informações colhidas na página dedicada ao Professor pela Universidade de Waterloo, disponível em < https://bulletin.uwaterloo.ca/2010/apr/28we.html>.
} 
PERYM, Damião de Froes. Theatro heroino: abecedario historico, e catalogo de mulheres illustres em armas, letras, acçoens heroicas e artes liberais: offerecido à Sereníssima Princeza do Brasil, D. Mariana Victoria. Lisboa: Officina Sylviana; Academia Real, [1740]. v. 2.

PIMENTEL, Soror Maria de Mesquita. Memorial da infancia de Christo e triumpho do divino amor: poemas em dez cantos de oytava rythma. Lisboa: Officina de Pedro Craesbeeck, 1638.

PIMENTEL, Soror Maria de Mesquita. Memorial da infancia de Christo e triumpho do Divino Amor: primeira parte. Lisboa: Officina de Jorge Rodriguez, 1639.

PIMENTEL, Soror Maria de Mesquita. Memorial da Infância de Cristo e Triunfo do Divino Amor (primeira parte). Prefácio de Adma Muhana. Organização, notas e estudos introdutórios de Fabio Mario da Silva. São Paulo: Todas as Musas, 2016.

PIMENTEL, Soror Maria de Mesquita. Memorial dos Milagres de Cristo e Triunfo do Divino Amor (segunda parte). Prefácio de José Augusto Cardoso Bernardes. Organização, notas e estudos introdutórios de Fabio Mario da Silva. São Paulo: Todas as Musas, 2017.

PIMENTEL, Soror Maria de Mesquita. Memorial da Infância de Cristo e Triunfo do Divino Amor (primeira parte). Prefácio de Adma Muhana. Segunda edição revisada e aumentada. Organização, notas e estudos introdutórios de Fabio Mario da Silva. São Paulo: Todas as Musas, 2019.

PIMENTEL, Soror Maria de Mesquita. Memorial da Paixão de Cristo e Triunfo do Divino Amor (terceira parte). Prefácio de Christina Ramalho. Organização, notas e estudos introdutórios de Fabio Mario da Silva. São Paulo: Todas as Musas, 2019.

SILVA, Fabio Mario da. Estudos Introdutórios. In: PIMENTEL, Soror Maria de Mesquita. Memorial da Infância de Cristo e Triunfo do Divino Amor (primeira parte). Prefácio de Adma Muhana. Organização, notas e estudos introdutórios de Fabio Mario da Silva. São Paulo: Todas as Musas, 2016, p.16-64.

SILVA, Inoccencio Francisco da. Diccionario Bibliographico Portuguez, Tomo VI, Lisboa, Imprensa Nacional, 1862, p. 141-142.

UNIVERSIDADE DE WATERLOO. Math founder Ralph Stanton dies at 86. In: Daily Bulletin, 28 de abril de 2010, disponível em <https://bulletin.uwaterloo.ca/2010/apr/28we.html>, acesso em 12 de março de 2020. 